\title{
W.G. Sebald como leitor de Ernst Herbeck, o mais pobre dos poetas
}

\section{W.G. Sebald as a reader of Ernst Herbeck, the poorest of the poets}

\author{
Ruth Bohunovsky \\ Universidade Federal de Santa Catarina \\ ruth.bohunovsky@uol.com.br
}

Resumo: Este artigo tem como tema a presença do escritor austríaco Ernst Herbeck na obra literária e em ensaios de teor crítico-teórico de W.G. Sebald e se divide em três partes: uma tentativa de compreender a prioridade que escritores austríacos ocupam nos ensaios sobre literatura escritos por Sebald; uma apresentação de Ernst Herbeck, autor ainda desconhecido no Brasil; uma discussão sobre Sebald enquanto leitor de Herbeck. O olhar que Sebald lança sobre Herbeck será definido como único e, ao mesmo tempo, paradigmático no âmbito da obra crítico-literária do escritor alemão.

Palavras-chave: W.G. Sebald; Ernst Herbeck; literatura austríaca.

\begin{abstract}
This article focuses on the presence of the Austrian writer Ernst Herbeck in the literary and critical-theoretical texts of W.G. Sebald and is divided into three parts: an attempt to understand the priority that Austrian writers occupy in the essays on literature written by Sebald; a presentation of Ernst Herbeck, a still unknown author in Brazil; a discussion of Sebald as a reader of Ernst Herbeck. The look Sebald throws on Herbeck is unique and, at the same time, paradigmatic in the context of the critical texts of the German writer.
\end{abstract}

Keywords: W.G. Sebald; Ernst Herbeck; Austrian literature. 


\section{W.G. Sebald e a literatura austríaca ${ }^{1}$}

Em tempos de hibridismo e de transculturalidades, pensar sobre literatura e/ou história literária em moldes nacionais parece algo ultrapassado. Já em 1931, posicionando-se contra a busca de interpretações totalizantes e hegemônicas, Walter Benjamin se opôs ao "caráter representativo vazio" das histórias literárias tradicionais, baseadas na ideia do nacional e feitas para o "uso caseiro da burguesia" (BENJAMIN, 1931). Desde então, as histórias literárias na tradição do século XIX - estreitamente ligadas à formação da ideia de uma nação cujo suposto caráter se expressasse, sobretudo, por meio de uma literatura nacional - foram alvo de constantes críticas.

W.G. Sebald publicou dois volumes de ensaios dedicados explicitamente à literatura austríaca: Die Beschreibung des Unglücks: zur österreichischen Literatur von Stifter bis Handke [A descrição da infelicidade - sobre a literatura austríaca de Stifter até Handke], cuja primeira edição data de 1985, e Unheimliche Heimat: Essays zur österreichischen Literatur [A Pátria inpátrida - ensaios sobre a literatura austríaca], lançado em 1991. Esses dois livros já indicam que, embora nunca tenha se debruçado sobre a questão das múltiplas diferenças entre a literatura austríaca e outras literaturas em língua alemã, Sebald deixou claro que considera a existência de uma tradição literária específica da Áustria um fato. Mas: existe uma literatura austríaca? Será que ela possui tradições, peculiaridades e uma historiografia diferentes daquela da Alemanha? As discussões acerca dessa questão são antigas - elas remetem ao século XVII ${ }^{3}$ - e continuam polêmicas.

Estaria Sebald, com seus dois livros sobre a literatura austríaca, atribuindo uma importância indevida a fronteiras nacionais quando pensa em literatura e, consequentemente, correndo o risco de ser acusado de defensor de uma visão obsoleta?

\footnotetext{
${ }^{1}$ Agradeço a Cristiane Gonçalves Bachmann pela revisão cuidadosa deste artigo e pela permissão de citar suas

2 Todas as traduções são minhas, salvo menção em contrário.

${ }^{3}$ Na primeira metade do século XVII, os irmãos Bernhard e Hieronymus Petz, por exemplo, insistiram numa tradição literária austríaca peculiar, caracterizada pela sua suposta oposição à "erudição protestante" (ZEYRINGER, GOLLNER, 2012, p. 48).
} 
$\mathrm{Na}$ tentativa de contextualizar a discussão sobre a existência/inexistência de uma literatura específica da Áustria, podemos recorrer, novamente, a Walter Benjamin - que, no mesmo texto citado acima, ressalta a urgência de conferir maior destaque a reflexões sobre aquilo que hoje podemos chamar de sistema literário, isto é, as relações entre a produção literária e fatores socioeconômicos, as editoras e livrarias, as associações dos escritores, o perfil sociológico dos leitores, as novas tecnologias ligadas à escrita e à divulgação de literatura, entre outros fatores (BENJAMIN, 1931). Partindo de tal compreensão de sistema literário, que não necessariamente engloba toda a produção literária de determinada língua, a germanística austríaca atual tende a reforçar a importância de se pensar o sistema literário do seu país como autônomo, embora não independente, em relação aos sistemas literários de outros países de língua alemã, sobretudo da Alemanha. Defende-se que as diferenças culturais, políticas, econômicas, religiosas e sócio-históricas entre os territórios que fizeram parte do império austro-húngaro e aqueles que se uniram em 1871 como Alemanha seriam significantes demais para serem ignoradas e explicam a necessidade de se estudar a literatura da Áustria na sua especificidade ${ }^{4}$. Com isso, a germanística austríaca assume uma postura contrária à tendência de incorporar a produção literária da Áustria à "literatura alemã" ou, até, à "literatura da Alemanha" .

Mas voltemos a W.G. Sebald - que, talvez suspeitando da dimensão relativa e da inutilidade de tal empreendimento, nunca tentou chegar a uma definição exata do que seria a literatura austríaca. Porém, no conjunto dos textos ensaísticos, teóricos e críticos que escreveu sobre literatura, a maioria trata de escritores desse país. Sebald é, segundo a contagem de Uwe Schütte, autor de 30 artigos sobre autores e temas austríacos e de apenas dez ensaios sobre literatos alemães (SCHÜTTE, 2003, p. 2). Debruçar-se sobre o estudo de escritores austríacos - e, sobretudo, defini-los como tais - é parte integrante do ímpeto de Sebald de pôr em questão conceitos e premissas teóricas tidos como certos pela germanística considerada mainstream.

\footnotetext{
${ }^{4}$ Ver, por exemplo, Gollner, Zeyringer (2012); Zeman (2014).

${ }^{5}$ Como um dos inúmeros exemplos dessa tendência inclusiva podemos citar aqui o livro Deutschland erzählt: von Rainer Maria Rilke bis Peter Handke [Narrativas da Alemanha: de Rainer Maria Rilke até Peter Handke], lançado pela editora Fischer em 1977 e reeditado diversas vezes até os anos de 1990.
} 
Já nos seus primeiros trabalhos acadêmicos, Sebald manifestou a tendência de rebater ideias e interpretações tidas como certas pela maioria dos seus colegas - por exemplo, no seu trabalho de mestrado, cujo objetivo foi "revisar a imagem de Sternheim posta em circulação pelos estudos germanísticos" (SCHÜTTE, 2003, p. 3). Uwe Schütte, num pequeno texto em que relata suas experiências como orientando de pós-graduação do professor de literatura W.G. Sebald, residente na cidade inglesa de Norwich, fornece um exemplo ilustrativo da postura de outsider do seu orientador. Nos encontros semanais dos dois, a rotina era sempre a mesma: Schütte fazia uma pequena apresentação de um livro, seguindo o modelo de análise literária que havia aprendido na Universidade de Munique - "um resumo do enredo, uma reflexão sobre os textos críticos, seguido da tentativa de chegar a uma interpretação baseada na fortuna crítica disponível” (SCHÜTTE, 2016, p. 1). Durante a fala do seu discípulo, Sebald costumava observar "pacientemente" o seu orientando, para, depois de terminada a apresentação padrão, "embarcar numa fala improvisada que ignorava todas as outras opiniões dos críticos" (SCHÜTTE, 2016, p. 1). Sebald costumava ou apresentar "uma avaliação que diferia consideravelmente da opinião aprovada pela maioria" ou "identificar algum detalhe da obra que passasse geralmente despercebido, para nele basear sua aprovação ou reprovação" (SCHÜTTE, 2016, p. 1).

Sem aliar-se de modo estável a uma tendência teórica, Sebald simpatizava com visões minoritárias dentro da sua área de estudo. E uma dessas minorias é justamente o que podemos chamar de "germanística austríaca", que entende o conceito de uma "literatura em língua alemã" como insuficiente para dar conta da heterogeneidade dos diversos sistemas literários existentes em meio à totalidade da produção literária em língua alemã. Partir da premissa de que existe uma literatura austríaca autônoma - mesmo que não independente - em relação à alemã implica automaticamente pedir uma revisão do imaginário dominante segundo o qual haveria uma literatura em língua alemã em cujo corpus questões de nacionalidade teriam pouca ou nenhuma relevância. ${ }^{6}$ Assim como, para Gilles Deleuze e Félix Guattari, as "literaturas menores" são escritas contra a dominância de uma "literatura maior" (sem que isso implique algum juízo de valor), a germanística austríaca poderia ser definida como um

\footnotetext{
${ }^{6}$ Ver, por exemplo, Carpeaux (2013); Schlaffer (2013).
} 
"germanística menor", assumindo o papel fundamental de colocar em questão categorias, valores e certas posições teóricas da germanística "maior", mainstream. Vem ao encontro de tal interpretação o comentário de Schütte de que o olhar do seu professor para a literatura austríaca deve ser entendido como um "contraponto do chauvinismo cultural - lamentado por Sebald em diversas ocasiões - que os alemães mostram em relação aos austríacos e que se manifesta, por exemplo, na eliminação de especificidades linguísticas austríacas pelos revisores das grandes editoras alemãs" (SCHÜTTE, 2002, p. 125).

Sebald foi definido por Uwe Schütte como "talvez o mais austríaco dentre os escritores alemães contemporâneos" (2002, p. 124). Em vista disso, sua tendência a associarse a vertentes, escritores e métodos investigativos que não faziam parte do mainstream parece mais que coerente (cf., também, SCHÜTTE, 2007). Além dos motivos acadêmicos, há outros - biográficos e pessoais - que também contribuem para entender o grande interesse de Sebald pela literatura austríaca. $O$ escritor passou sua infância na região de Allgäu, mais próxima da Áustria rural do que da capital do estado da Baviera. Assim como muitos autores oriundos de províncias austríacas, Sebald viu na literatura uma possibilidade de libertar-se das pressões que sofria devido à sua origem nas margens da sociedade e, "assim como eles, teve de constatar que tal ato emancipatório significou também uma expulsão" (SCHÜTTE, 2003, p. $5)$.

Longe de lançar-se em busca de algo como a "essência" da literatura austríaca ou de qualquer coisa que expressasse alguma característica intrínseca das obras literárias provenientes de autores austríacos ou, ainda, de uma definição de "literatura nacional" nos moldes do século XIX, Sebald pôs-se à procura de "complexidades específicas" da literatura austríaca que lhe pareciam "constituintes" de seu sistema literário (SEBALD, 2006, p. 9). De acordo com Schütte, tais "complexidades" que Sebald distinguiu no âmbito da literatura austríaca vieram ao encontro não só dos seus interesses acadêmicos anti-mainstream, mas também de seus interesses pessoais, e explicam a sua empatia e identificação que sentiu com os escritores sobre os quais escreveu. As "complexidades" definidas por Sebald podem ser divididas em dois grupos temáticos - que se refletem, aliás, nos títulos das duas coletâneas sobre a literatura austríaca que ele publicou: trata-se, de um lado, da problemática em torno de 
assuntos como pátria, expulsão e exílio; e, de outro lado, do conjunto psicopatologia, melancolia e infelicidade. ${ }^{7}$

Ernst Herbeck - cuja presença na obra de Sebald é o que nos interessa aqui - faz parte do segundo grupo temático, que reúne autores de obras reveladoras no que diz respeito a questões como infelicidade, melancolia e psicopatologia. Para Sebald, vários escritores austríacos - Arthur Schnitzler, Hugo von Hofmannsthal, Elias Canetti, Peter Handke etc. fornecem um "material para o estudo da formação e deformação psíquica" que vai muito além daquilo que sabemos por intermédio da ciência (SEBALD, 2006, p. 9). Nos seus ensaios, Sebald revela um olhar atento, sensível e tolerante para com as fraquezas humanas e uma enorme empatia com os excluídos, aqueles que foram vencidos pela (sua) história e/ou por sua "deformação psíquica". Com base num sistema de referências na tradição do humanismo, Sebald colocava o homem no centro da sua atenção, pondo em destaque

o homem emancipado do século XX, consciente da sua capacidade de atuação política autodeterminada, mas que, ao mesmo tempo, se confronta com a prevalência dos processos históricos; que põe sua individualidade contra o coletivo, embora geralmente fracasse nessa tentativa. (SCHÜTTE, 2003, p. 6).

Fascinado principalmente pelos "fracassos" humanos, Sebald tornou-se o "anatomista da melancolia" (GÖRNER, 2003), atraído pela "reflexão sobre a infelicidade" (SEBALD, 2006, p. 12). Definiu como “objeto central” das suas análises, reunidas em Die Beschreibung des Unglücks..., a "infelicidade do sujeito-escritor" (SEBALD, 2006, p. 11), e aponta que esse traço já teria sido destacado por outros teóricos como uma "característica essencial" da literatura austríaca:

aqueles que escolhem a literatura como profissão geralmente não pertencem à categoria das pessoas mais alegres e despreocupadas, mas a frequência de vida infelizes na história da literatura austríaca é enorme e explica a inclinação negativa dessa literatura [...]. (SEBALD, 2006, p. 11)

Sem abrir mão da primazia do texto nas suas análises, em todos seus ensaios, Sebald dedica atenção especial à relação entre o texto, o autor e o contexto em que surgiu a obra,

\footnotetext{
7 A esses dois grupos, Schütte acrescentou mais dois, também onipresentes na obra de Sebald e interrelacionados com os dois principais: o que abrange o tema "amor/relacionamentos"; e o que apresenta como tema a "natureza". (SCHÜTTE, 2003, p. 6).
} 
afastando-se, assim, das "ideias pós-modernas" que entendem a literatura "como a soma de discursos que se criam mutuamente num vácuo" (SCHÜTTE, 2003, p. 7). Sebald interessa-se pelo homem - que aqui não deve ser entendido como sinônimo de "ser humano", mas referindo-se especificamente a seres humanos do sexo masculino, já que Sebald não dedicou nenhum ensaio a mulheres escritoras - e por aquilo que há de infeliz, de perturbado, de mal resolvido e de perverso nele, ou seja, por tudo aquilo que geralmente se esconde por trás da fachada da civilização. Na leitura de Sebald, Adalbert Stifter, por exemplo - o suposto poeta "das flores e dos besouros", tão representativo do Biedermeier - revela-se como um sujeito sofredor com tendência à pedofilia (SEBALD, 2006, p. 61); Arthur Schnitzler espelha toda a descrença possível no conceito humanista de amor, e Hugo von Hofmannsthal explora, no seu fragmento Andreas, as "forças centrifugais da sua e das nossas vidas", que têm em vista a “deformação e a destruição" (SEBALD, 2006, p. 63).

Sebald entende a melancolia como uma "forma de resistência" e acredita que "a descrição da infelicidade inclui a possibilidade de sua superação" (SEBALD, 2006, p. 12), referindo-se, por exemplo, a Thomas Bernhard e Peter Handke como "duas pessoas bemhumoradas e animadas, apesar dos seus mergulhos na história das calamidades da humanidade" (SEBALD, 2006, p. 12). Esse pequeno comentário sobre Bernhard e Handke é, aliás, bastante ilustrativo do olhar anti-mainstream de Sebald que, ao caracterizar os dois famosos austríacos como pessoas "bem-humoradas e animadas", afasta-se do lugar comum de enxergar sobretudo Thomas Bernhard como uma pessoa negativa, misantrópica, depressiva e mal-humorada. Porém, obviamente, o objetivo do "anatomista da melancolia" não é revelar a infelicidade como uma felicidade bem disfarçada; ele sabe que a melancolia e a infelicidade podem, também, levar à morte, ao suicídio e para além dos limites daquilo que é socialmente aceito.

A psicopatologia é tema de diversos textos sebaldianos. Em "Unterm Spiegel des Wassers - Peter Handkes Erzählung von der Angst des Tormanns" [“Abaixo do espelho d'água - a narrativa de Peter Handke sobre o medo do goleiro"], um dos textos que fazem parte da coletânea Die Beschreibung des Unglücks..., Sebald define o referido texto de Handke como uma "descrição empática" da passagem da "normalidade" para a "loucura" que 
o goleiro Bloch vivencia, na sua fuga esquizofrênica da realidade (SEBALD, 2006, p. 116). Embora escrito em terceira pessoa, o texto de Handke assume a perspectiva interior do personagem principal, o goleiro Bloch, revelando, assim, os sintomas da fase inicial da sua psicose. O termo-chave na análise de Sebald sobre a "realidade interna" (SEBALD, 2006, p. 117) do goleiro à beira da desintegração psíquica é a empatia, e não uma suposta "onisciência autoral" (SEBALD, 2006, p. 117) racionalista. Sebald ressalta que Handke, ancorado na filosofia wittgensteiniana e na "tradição austríaca do ceticismo linguístico" (SEBALD, 2006, p. 122), é capaz de demonstrar a "desintegração 'patológica' da capacidade linguística" do protagonista, assim como seu "olhar patológico que capta permanentemente tudo" e que se revela como "o modo mais precisa de percepção" (SEBALD, 2006, p. 122). Lançando mão da forma literária, Handke evita que o discurso do goleiro seja apenas um "murmúrio autista" e consegue transformá-lo numa "metaficção de um texto literário" (SEBALD, 2006, p. 123). Segundo Sebald, o que torna Handke capaz de expressar tamanha empatia na sua representação de uma visão de mundo patológica é o fato de seu maior interesse ser, em última instância, "seu próprio distanciamento da vida "normal", o "estudo da sua própria consciência 'carregada de culpa' de um artista" (SEBALD, 2006, p. 129). Algo semelhante pode, sem dúvida, ser dito sobre o próprio Sebald e sua empatia com os autores cujas obras e vidas estudou - logo no início do seu ensaio sobre Herbeck, o teórico ressalta, por exemplo, que "o entendimento da própria insuficiência [...] seria certamente o ponto de partida adequado" para um estudo sobre a arte de Ernst Herbeck (SEBALD, 2006, p. 132).

Sebald interessava-se pelo sujeito deslocado - fosse ele autor ou personagem ficcional. Esse deslocamento se manifesta sempre na e por meio da linguagem, e é justamente essa relação entre o homem, o texto e seu contexto que Sebald coloca em primeiro plano nas suas análises. Não surpreende, portanto, que a figura de Ernst Herbeck seja tão presente na sua obra, tanto como personagem literária quanto como objeto de estudo, a exemplo do que se lê em seu ensaio Eine kleine Traverse: Das poetische Werk Ernst Herbecks [Uma pequena transversal: a obra poética de Ernst Herbeck]. Mais do que qualquer outro dos autores abordados pelo estudioso alemão, Herbeck simboliza o deslocamento da "normalidade" socialmente aceitável, dos padrões literários, da linguagem racional. Além disso, Herbeck é o 
único autor no conjunto de nomes estudados nos dois volumes sobre a literatura austríaca escritos por Sebald que definitivamente não fazia parte do cânone literário da época. Levando também em conta o fato de que ele, até hoje, não teve senão uma recepção ainda incipiente via tradução e/ou crítica no Brasil, ${ }^{8}$ dedicamos o presente artigo a uma discussão sobre esse poeta e seu papel na obra de W.G. Sebald.

\section{Vida e obra de Ernst Herbeck, o mais pobre dos poetas}

Uma característica da literatura de Sebald é a presença de "autores convidados"- entre eles, Franz Kafka, Joseph Conrad e o filósofo Sir Thomas Browne. Muitas vezes, trata-se de pessoas marcadas por uma relação complexa com seu próprio passado, com dificuldade de superar velhos traumas. Um desses "autores convidados" é Ernst Herbeck, que Sebald havia conhecido por intermédio do escritor austríaco Gerhard Roth. Em Schwindel, Gefühle [Vertigem], dedica nove páginas ao relato de uma das visitas que fez ao poeta austríaco, em outubro de 1980. Antes de iniciar o relato propriamente dito, Sebald oferece ao leitor algumas informações básicas sobre a vida de Herbeck:

Ernst Herbeck sofre de distúrbios mentais desde os vinte anos. Foi internado pela primeira vez numa clínica em 1940. Até essa data, trabalhara como auxiliar numa fábrica de materiais bélicos. De repente, mal pôde mais comer ou dormir. Ficava acordado à noite, contando em voz alta. O corpo de contorcia. A vida familiar, sobretudo o pensamento incisivo do pai, lhe corroía os nervos, como ele dizia. Acabou por perder o controle sobre si mesmo, atirava o prato para longe durante as refeições ou entornava a sopa debaixo da mesa. Às vezes, seu estado melhorava por algum tempo. Em outubro de 1944 foi até recrutado pelo Exército, mas deu baixa novamente em março de 1945 . Um ano após a guerra, foi internado pela quarta e última vez. Passava as noites vagando pelas ruas de Viena, chamando a atenção pelo seu comportamento, e prestou declarações confusas à polícia. No outono de 1980 , depois de trinta e quatro anos de internação, atormentado a maior parte desse tempo pela estreiteza de seus próprios pensamentos e apreendendo a realidade como através de um véu diáfano diante dos olhos, Ernst Herbeck recebeu alta a título de

\footnotetext{
${ }^{8}$ Em 2016, Cristiane Gonçalves Bachmann, bolsista de iniciação científica, deu início à tradução da obra poética de Ernst Herbeck, no âmbito de um projeto de pesquisa na Universidade Federal do Paraná, e algumas de suas traduções serão reproduzidas ao longo deste artigo.
} 
experiência e foi aposentado por invalidez. Agora vivia num asilo da cidade, entre internos dos quais ele mal se destacava. (SEBALD, 2008, p. 35).

Já em 1981, um ano após sua saída, Herbeck voltou por vontade própria à clínica psiquiátrica de Gugging e não a deixou mais até a sua morte, em 1991. Durante toda a sua vida, Herbeck sofria pelas implicações de uma fissura labiopalatal, malformação congênita responsável por sua grave deficiência de fala. Ou seja: Herbeck praticamente não conseguia se expressar na oralidade, sua fala era quase incompreensível.

No mesmo ano em que Herbeck entrou na clínica de Gugging, em 1946, o jovem médico psiquiatra Leo Navratil iniciou sua carreira nessa instituição. Ao longo dos 45 anos de convívio entre os dois, Navratil construiu sua reputação como pesquisador, incentivador e promotor de uma forma de criação artística condicionada ao estado psíquico do artista [zustandsgebundene Kunst], mais conhecida como art brut [arte bruta ou primitiva] ou outsider art. Em Gugging, criou a Casa dos Artistas [Haus der Künstler], onde os pacientes encontraram um ambiente propício para a produção artística.

Sebald deixou de mencionar na pequena nota biográfica citada acima que, ao longo dos mais de trinta anos de internação, Herbeck produziu uma obra poética bastante singular, tornando-se o mais famoso paciente-poeta da Casa dos Artistas. Sobre o início de sua relação com o paciente e da sua produção literária, conta o médico Navratil:

[...] tentei estabelecer uma relação mais próxima com ele. Ele mencionou seu problema de fala. Tentei convencer-lhe de não se isolar, apesar dessas dificuldades. Nessa época, já pedia a muitos pacientes para fazerem desenhos. E pedi também a Herbeck para desenhar algo, pedi que escrevesse sua biografia e relatasse por escrito tudo que ocorreu ao longo do dia. Herbeck cumpriu essas tarefas com boa vontade, mas não parecia muito convencido de que aquilo fizesse sentido; porém, foram tentativas de comunicação, também da sua parte. (NAVRATIL, 1992, p. 209).

Porém, a partir do momento em que Navratil lhe pediu a escrever um poema - e não mais um texto narrativo -, a escrita deixou de ser mera ferramenta de comunicação: "De repente, tinha em mãos algo interessante, não apenas em termos psicopatológicos; tratava-se de um verdadeiro poema" (NAVRATIL, 1992, p. 213). A escrita dos aproximadamente 1.200 poemas e textos curtos em prosa de Herbeck deu-se nas seguintes condições: 


\begin{abstract}
Herbeck só escrevia quando solicitado e praticamente apenas após receber o título. Só realizava alterações e correções durante a escrita, nunca depois. Não guardou nenhum poema nem jamais decidiu quais deles seriam publicados. Nenhum dos textos que Herbeck escreveu foi destruído. [...] Nos anos de 1966, 1977, 1979 e 1982, algumas partes mais extensas dessa obra foram publicados em livros. (NAVRATIL, 1992, p. 5).
\end{abstract}

Navratil aponta que os textos de Herbeck - que se autodeclarou "um dos pacientes mais pobres" do seu médico (NAVRATIL, 1992, p. 210) - “continham muitas características da esquizofrenia; porém, ao mesmo tempo, eram poesia” (NAVRATIL, 1992, p. 214). Essa sobreposição de esquizofrenia e literatura é, também, um aspecto fundamental na análise que W.G. Sebald apresenta sobre o poeta de Gugging.

A primeira publicação de poemas de Herbeck integrou o livro Schizophrenie und Sprache [Esquizofrenia e Linguagem] ${ }^{9}$, de 1966, organizado por Navratil. Os poemas não constam dessa obra apenas como exemplos ilustrativos de um estudo psiquiátrico: já se ressalta o valor literário da linguagem herbeckiana. A recepção do livro ultrapassou sobremaneira as expectativas do médico, "muitas pessoas se mostraram extremamente impressionadas com os poemas de Herbeck" (NAVRATIL, 1992, p. 214), entre as quais, artistas de renome como Otto Breicha, André Heller, Ernst Jandl, Friederike Mayröcker, Reinhardt Priessnitz e Gerhard Roth (NAVRATIL, 1992, p. 219). Apesar dos seus problemas de articulação, Herbeck fez diversas leituras públicas dos seus poemas. Em 1978, foi eleito membro da Associação dos Escritores de Graz (NAVRATIL, 1992, p. 219). Apenas a germanística não mostrou interesse pelo poeta - com exceção de W.G. Sebald, que, de acordo com Schütte, "foi o primeiro germanista que reconheceu a qualidade literária dos poemas de Herbeck e que se debruçou seriamente sobre eles" (SCHÜTTE, 2003, p. 7-8).

A produção literária de Herbeck mudou ao longo dos anos e foi dividida por Navratil em fases, seguindo a ordem cronológica: nos primeiros anos, entre 1960 e 1966, Herbeck estava muito "inibido" no que tangia à sua psicomotricidade (NAVRATIL, 1999, p. 7). São dessa fase, por exemplo, os poemas "Das Leben" e "Die Wolken":

\footnotetext{
${ }^{9}$ Por questões legais, o nome do autor não podia ser citado. Navratil recorreu, então, ao pseudônimo "Alexander".
} 


\begin{tabular}{|l|l|}
\hline Das Leben & A vida \\
$\begin{array}{l}\text { Das leben ist schön } \\
\text { Schön so schön als das Leben. }\end{array}$ & A vida é bela \\
$\begin{array}{l}\text { Das Leben ist sehr schön } \\
\text { das lernen wir; das Leben; }\end{array}$ & Bela tão bela quanto a vida. \\
Das Leben ist sehr schön. & aprendemos nós; a vida; \\
Wie schön ist das Leben. & A vida é belíssima. \\
Es fangt schön an das Leben. & Quão bela é a vida. \\
So (schön) schwer ist das es auch. & Começa bela a vida. \\
& Tão (belamente) difícil ela também o é. \\
(HERBECK, apud NAVRATIL, 1999, p. 10.) & (Tradução de Cristiane G. Bachmann) \\
\hline
\end{tabular}

\begin{tabular}{|l|l|}
\hline Die Wolken & As nuvens \\
die wolken so groß und weit & as nuvens tão grandes e vastas \\
die wolken so groß und weit & $\begin{array}{l}\text { as nuvens tão grandes e vastas } \\
\text { die wolken so groß und weit } \\
\text { as nuvens tão grandes e vastas } \\
\text { e nas rochas como se brotadas }\end{array}$ \\
$\begin{array}{l}\text { ein vorhang wie der osten so groß und } \\
\text { der wiederhall im tal war gut und schön }\end{array}$ & $\begin{array}{l}\text { o revérbero no vale era bom e belo } \\
\text { o parsifalho qis elevar o olhar para } \\
\text { und sah sah auch auf sie die da hernieder- } \\
\text { prasseln wie schnee und eis die regenntropfen }\end{array}$ \\
e viu viu acima as que ca- \\
íam como neve e gelo as gotas de chuva \\
(HERBCK, apud NAVRATIL, 1999, p. 19) & (Tradução Cristiane G. Bachmann) \\
\hline
\end{tabular}

Em 1967, após uma longa pausa, Navratil retomou as atividades literárias com Herbeck. Segundo o médico, "foi uma fase de abundante produção literária" (NAVRATIL, 1999, p. 43), o auge da vida poética do seu paciente, que agora estava "mais seguro de si e menos inibido" (NAVRATIL, 1999, p. 43). Suas "associações fluíam mais intensamente" (NAVRATIL, 1999, p. 43) e o número de estereótipos foi diminuindo, além de a linguagem e os pensamentos terem se tornado mais compreensíveis e mais claros (NAVRATIL, 1999, p. 43). Nessa fase, Herbeck escreveu, por exemplo, "Das Blut.” [“O sangue”] e alguns dos poemas que abordam questões da sua própria realidade como paciente de uma clínica psiquiátrica:

\begin{tabular}{|l|l}
\hline Das Blut. & O sangue. \\
\hline
\end{tabular} 
Das Blut ist die Wahrheit.

Die Schüler müssen sich einer Blutprobe unterziehen.

Es gibt ein A und O-Blut.

Das Blut gibt Ausdruck über den Körperbau.

Je schwerer der Mensch ist, desto mehr Blut hat er.

(HERBECK, apud NAVRATIL, 1999, p. 49.)
O sangue é a verdade.

Os estudantes devem submeter-

se a um hemograma.

Há um A e um sangue $\mathrm{O}$.

O sangue revela sobre o biotipo.

Quanto mais pesado é o homem, tanto mais sangue ele tem.

(Tradução de Cristiane G. Bachmann)
Patient und Dichter

Je größer das Leid desto kleiner der Dichter

Umso härter die Arbeit

Umso tiefer der Sinn

Je größer das Unheil

desto härter der Kampf

Umso ärger der Verlust

desto irrsinniger die Verdammten.

(HERBECK, apud NAVRATIL, 1999, p. 68.)
Paciente e Poeta

Quanto maior a dor tanto menor o poeta

Tão mais árduo o labor

Tão mais profundo o sentido

Quanto maior a desdita

tanto mais árdua a luta

Tão maior o prejuízo

Tão mais doidos os condenados.

(Tradução de Cristiane G. Bachmann)

O poema "Die Sprache" ["A língua”], também da segunda fase, é um dos muitos poemas que fazem menção ao mundo animal:

Die Sprache.

$a+b$ leuchten im Klee.

Blumen am Rande des Feldes.

Die Sprache. -

die Sprache ist dem Tier verfallen.

und mutet im $a$ des Lautes.

das $c$ zischt nur so umher und

ist auch kurz dann sein

Gewehr.

(HERBECK, apud NAVRATIL, 1999, p. 44.)
A língua.

$b+a$ cintilam no patuá.

Flores à beira do prado.

A língua. -

a língua é dependente dos animais.

e sonha no $a$ da soada.

o $c$ cicia só assim ao redor $\mathrm{e}$

é também num instante sua

arma.

(Tradução de Cristiane G. Bachmann) 
Como destaca Gisela Steinlechner, Herbeck sentia uma grande "afinidade eletiva" com o mundo animal. Os animais seriam os "ágeis avatares da sua tristeza", pois, na sua infância, devido à sua dificuldade de fala, muitas pessoas teriam se dirigido a ele usando nomes de animais (STEINLECHNER, 2013, p. 250). Seu animal preferido era a lebre, personagem recorrente na sua poesia, mas diversos outros animais estão presentes em seus poemas, podendo-se dizer que criou um rico bestiário, tratando tanto da girafa e da zebra como da pantera e do camelo, mas também da coruja e do canarinho, como neste poema da terceira fase:

\begin{tabular}{|l|l|}
\hline Kanarienvogel & Canarinho \\
$\begin{array}{l}\text { Kanarienvögel sind im Käfig drin, } \\
\text { warten auf das Frühgeschehen am } \\
\text { Morgen ganz und gar. } \\
\begin{array}{l}\text { Insoweit ist er vergnügt und singt, } \\
\text { weil er singt und sich auch badet } \\
\text { und dann wieder singt. }\end{array}\end{array}$ & $\begin{array}{l}\text { Os canarinhos nas gaiolas } \\
\text { esperam pelo alvorejar na } \\
\text { manhã absoluta. } \\
\text { E nisso, gaiteiro, ele canta } \\
\text { porque ele canta e se banha } \\
\text { e então recanta. }\end{array}$ \\
$\begin{array}{l}\text { Der Kanarienvogel hört und sieht } \\
\text { sich die Möbel an. Er ist riesig } \\
\text { unverdorben und hat ein gelbes } \\
\text { Gefieder an. }\end{array}$ & $\begin{array}{l}\text { O canarinho vê e ouve } \\
\text { a mobília. Gigantemente } \\
\text { cândido, ele veste amarela } \\
\text { plumagem. }\end{array}$ \\
$\begin{array}{l}\text { Hören Sie sich, unverdorben, Sie sich das } \\
\text { mal an. }\end{array}$ & Ouça, candidamente ouça. \\
(HERBECK, apud NAVRATIL, 1999, p. 153) & (Tradução Cristiane G. Bachmann) \\
\hline
\end{tabular}

Na terceira fase (de 1969 a 1976), Navratil passou a apresentar a Herbeck alguns poemas de autores consagrados, como estímulo para a própria escrita. Herbeck não havia lido nenhum texto literário desde sua juventude, mas aceitou a proposta. Um exemplo do resultado dessa interlocução:

\begin{tabular}{|l|l|}
\hline $\begin{array}{l}\text { Wanderes Nachtlied } \\
\text { (zu Goethe) }\end{array}$ & $\begin{array}{l}\text { Noturno do errante } \\
\text { (sobre Goethe) }\end{array}$ \\
$\begin{array}{l}\text { Elender Schmerz, du heilen tust, } \\
\text { in Waldes Einsamkeit, Erquickung } \\
\text { fühlst. Der Umstand selbst ist }\end{array}$ & $\begin{array}{l}\text { Agônica dor, que tem alívio, } \\
\text { na solidão da floresta, encontra } \\
\text { lenitivo. A condição em si }\end{array}$ \\
\hline
\end{tabular}




\begin{tabular}{|l|l|}
\hline dieses Lied. & é esta canção. \\
& (Tradução Cristiane G. Bachmann) \\
\hline
\end{tabular}

Em 1980, foi revogada a necessidade de Herbeck viver sob tutela legal. Embora tenha voltado à clínica em 1981, por vontade própria, tornou-se possível a publicação de seus poemas sob seu nome verdadeiro. Como título do livro, escolheu-se o pseudônimo sob o qual seus textos haviam sido publicados anteriormente: Alexander. Nessa terceira fase, Navratil estimulou a colaboração com Oswald Tschirtner, também paciente da Casa dos Artistas de Gugging e um dos seus pintores mais renomados. Nos últimos dez anos de sua vida (19821991), Herbeck escreveu pouco. Em 1986, Navratil aposentou-se, e, com isso, acabou o “diálogo" entre os dois (NAVRATIL, 1999, p. 176).

\section{W.G. Sebald como leitor de Ernst Herbeck}

Um dos primeiros leitores do livro Schizophrenie und Sprache foi W.G. Sebald. Em Campo Santo (ainda sem tradução no Brasil), encontramos a seguinte passagem sobre esse contato literário:

\footnotetext{
Meu primeiro encontro com as figuras linguísticas excêntricas de Ernst Herbeck ocorreu em 1966. Lembro bem que, na Ryland's Library em Manchester, onde estava trabalhando num estudo sobre o infeliz Carl Sternheim, eu costumava pegar nos intervalos, para descansar um pouco a cabeça, o pequeno livro Schizophrenie und Sprache, e lembro como ficava impressionado com o brilho que emanava daquelas imagens de palavras e enigmas, unidos de modo aparentemente aleatório por esse mais pobre dos poetas. A todo instante encontram-se passagens cuja leve distorção e terna resignação nos fazem lembrar como a música de Matthias Claudius às vezes é capaz de nos dar, por um breve momento, a sensação de levitação. A admiração fica ainda maior ao perceber que Herbeck, além da sua prática poética, foi capaz de nos fornecer, em algumas poucas frases fundamentais, uma teoria poética completa (SEBALD, 2003, p. 171s.).
}

Sebald, quinze anos após esse primeiro contato com Herbeck, publica o ensaio Eine kleine Traverse... na revista Manuskripte e, em 1985, na coletânea Die Beschreibung des 
Unglücks... No prefácio desse livro, Sebald esclarece que não segue um único método nos seus ensaios, mas que, conforme as dificuldades com as quais se depara na redação dos textos, não hesita em "mudar, sem escrúpulos, o método analítico" (SEBALD, 2006, p. 9). Tal procedimento pode ser vulnerável a críticas por parte de uma germanística mais ortodoxa. $\mathrm{O}$ próprio Sebald justifica a heterogeneidade das suas referências teóricas a partir do seu objeto de estudo - a literatura austríaca -, que se distingue justamente por certo desrespeito a fronteiras aparentemente estáveis entre a arte e a ciência. Sebald aponta que seu procedimento "condiz com o desrespeito calculado com que a literatura austríaca trata os limites tradicionais entre, por exemplo, seu próprio campo de atuação e as ciências" (2006, p. 9). E é exatamente nesse diálogo sem fronteiras fixas que a literatura austríaca consegue chegar a percepções que, em muitos aspectos, superam a profundidade do conhecimento das ciências psicológicas. Tendo-se em conta essas premissas, não surpreende que Eine kleine Traverse..., assim como todos os outros ensaios reunidos nos dois volumes sobre a literatura austríaca, "se esquiva da clara separação entre o intérprete e o interpretado, implícita na pretensão de objetividade das ciências literárias" (SCHÜTTE, 2003, p. 8). Sebald salienta que pretende evitar a tendência da “explicação científica” de, "em respeito à própria lógica [...] omitir tudo aquilo que não corresponde aos próprios conceitos (SEBALD, 2006, p. 131). O melhor ponto de partida para uma aproximação adequada à obra de Herbeck seria, portanto, aceitar as "deficiências" no próprio conhecimento. Mais que ilustrar um suposto modelo teórico regularmente aplicado por Sebald, o artigo sobre Ernst Herbeck expõe justamente a prática pouco ortodoxa do autor.

Embora seu primeiro contato com Herbeck tenha sido por meio dos poemas e apesar de os textos sempre constituírem o ponto de partida das suas análises, Sebald põe o homem no centro da sua atenção e não pretende esconder sua empatia com autor e/ou personagem, mormente por trata-se de um excluído, um outsider. Para Schütte, o método de Sebald é um

procedimento mimético, que pouco tem a ver com a arbitrariedade do anything goes, mas que está atrelado a uma dedicação ao texto inspirada na hermenêutica e no qual este não é rebaixado a mero ponto de partida para a introspecção de algum método interpretativo visto de modo apodítico como algo absoluto (SCHÜTTE 2003, p. 8). 
Para aproximar-se dos textos de Herbeck com o respeito necessário, Sebald procura evitar o risco de usurpá-los, de "deleitar-se no excêntrico, às custas daquele que dele sofre" (SEBALD, 2006, p. 132). Com isso, distancia-se explicitamente da abordagem do escritor e dramaturgo alemão Heinar Kipphardt - autor de um romance e diretor de um documentário e de uma peça teatral sobre o poeta de Gugging —, que teria se entregado a uma "idealização heroica barata da doença mental, bastante comum desde o expressionismo" (SEBALD, 2006, p. 195), contrastando, assim, com a "intenção iluminista" do próprio Kipphardt e, sobretudo, "com o respeito que a obra de Herbeck, usada por Kipphart de modo tão generoso, teria merecido" (SEBALD, 2006, p. 195). Sebald toma outro rumo e decide compreender os textos de Herbeck "como a expressão de uma pessoa perfeitamente normal" (SEBALD, 2006, p. 132). Nesse ponto da sua argumentação, recorre a Walter Benjamin, citando uma passagem do seu ensaio Angelus Novus, em que o filósofo destaca que seria inútil "realçar de modo patético ou fanático o lado enigmático do enigmático; apenas somos capazes de apreender o mistério na medida em que o encontramos no cotidiano" (BENJAMIN 1966, p. 212s.; apud SEBALD, 2006, p. 132).

Tal abordagem se justifica por aquilo que os poemas de Herbeck têm em comum com qualquer poesia: "a capacidade de ver as coisas sob uma nova luz" (SEBALD, 2006, p. 132). A “fantasia poética” (SEBALD, 2006, p. 133) de Herbeck é comparável com a de outros poetas, faltando-lhe apenas a capacidade de participar dos discursos sociais de um modo considerado supostamente "normal". A “desintegração da linguagem" manifesta nos seus poemas é constitutiva e precondição de toda poesia - embora, no caso de Herbeck, seja atrelada à sua doença e não, como em casos de poetas ditos "normais", a certos "estados de agitação" (SEBALD, 2006, p. 132). A incapacidade (parcial) de participar dos discursos "normais" sobre poesia indica, portanto, "apenas uma deficiência social e não estética" (SEBALD, 2006, p. 133): “a única diferença entre a linguagem de Herbeck e aquela da literatura consagrada consiste no fato de Herbeck incluir na sua expressão o estado propedêutico do processo criativo, a dissociação como meio para a invenção de novas estruturas" (SEBALD, 2006, p. 135). 
Herbeck não participou da vida cultural fora dos muros da clínica, embora não tenha ficado completamente isolado de eventos artísticos. Em diversas ocasiões, leu seus poemas para um público de interessados. Posando de escritor, sempre acompanhado do seu livro e imitando os comentários críticos que os poetas costumam dar sobre sua obra, revelou nessas ocasiões um olhar bastante humorístico, autorreflexivo e revelador da "artificialidade da existência e do trabalho de um artista" (SEBALD, 2006, p. 137). Essa visão surge, por exemplo, na frase "Es werden die Künstler wie Semmeln gebacken. Preis 6gr." [“Os artistas são assados como os pãezinhos. Preço 6 centavos”] (SEBALD, 2006, p. 136). E, obviamente, Sebald não perde a chance de transformar a postura de Herbeck numa crítica indireta à própria classe de germanistas e literatos.

Do ponto de vista psicológico (e aqui o teórico recorre a Sigmund Freud), a desintegração discursiva pode ser vista como um "reservatório de energias regenerativas" (SEBALD, 2006, p. 133), pois “os sintomas de desintegração são, pelo menos potencialmente, o primeiro passo para uma nova relação entre sentimento, palavra e objeto designado" (SEBALD, 2006, p. 133). É por meio da condensação [Verdichtung] e do deslocamento [Verschiebung] que se procura voltar, com as palavras, aos objetos - ou, seguindo o raciocínio de Piaget, a uma "ampliação do pensamento normal” (SEBALD, 2006, p. 133). Declarações de Herbeck como "Der Regen ist die Traufe der Natur" [“A chuva é a goteira da natureza"] ou "Die Dame ohne Unterleib ist die Liebe in Berlin" ["A dama sem ventre é o amor em Berlim"] ganham, a partir de tal ponto de vista e apesar de sua "lógica deficitária", uma "considerável força sugestiva" (SEBALD, 2006, p. 133).

Para aproximar-se do processo criativo de Herbeck, Sebald recorre ao conceito de "fulguração", no sentido cunhado pelo zoólogo, etólogo e ornitólogo austríaco Konrad Lorenz. Trata-se de uma reinterpretação da antiga expressão de Aristóteles de que "o todo é maior do que a soma das partes": toda gênese seria um tipo de "curto-circuito", em que dois sistemas independentes entram em contato, levando ao surgimento de algo novo, cuja formação dependeria da "disponibilidade em livre flutuação dos componentes potenciais" (SEBALD, 2006, p. 134). Embora essa afirmação não se destaque pela sua clareza conceitual, talvez seja esse exatamente o objetivo de Sebald, em busca de evitar as respostas claras - 
porém insuficientes e deficitárias - da germanística e da "literatura ordenada" (SEBALD, 2006, p. 134). O momento da criação não é algo totalmente revelável e compreensível, mas dele surgem, mesmo no caso de um "doente mental" como Herbeck, que vagueia pelos "caminhos "errados", entendimentos "corretos", como nas frases "Es geht bergup in jenes Tal" ["Vamos pela montanha upaixo"] ou "Von hier in die Waldheimat Peter Roseggers in die Weltkriege" [“Daqui da pátria florestal de Rosegger até as Guerras Mundiais"] (SEBALD, 2006, p. 135).

Se o uso não utilitarista da linguagem é característico de todo pensamento simbólico, os textos de Herbeck diferenciam-se da poesia considerada "normal" no que são capazes de nos dizer sobre o ato da escrita experimental. Na vida de Herbeck, o ato da escrita possuía uma importância muito superior, em comparação ao que se verifica em outros poetas; "escrevendo, ele atravessa sua vida danificada" (SEBALD, 2006, p. 134), sem revelar, porém, nenhum interesse pelos textos já redigidos. Sebald resume: para o poeta de Guggin, "escrever é necessário, a literatura não" (SEBALD, 2006, p. 134). As interferências, a pontuação aleatória e as ideias aparentemente sem lógica que marcam os poemas de Herbeck são vistas por Sebald como o "correlato objetivo da coesão censurada da vida" do autor, são "marcações da sua situação pessoal de sofrimento" (SEBALD, 2006, p. 134).

Porém, Sebald rebate a impressão, que alguns dos seus argumentos poderiam sugerir, de que os poemas de Herbeck teriam sido criados sem técnica nenhuma. $O$ "modelo combinatório" usado por Herbeck poderia, segundo Sebald, ser associado ao conceito de bricolage, proposto por Lévi-Strauss para suas análises do pensamento mítico. De acordo com o antropólogo belga, um bricoleur seria alguém "que trabalha com suas mãos, usando meios que um especialista não ousaria" (LÉVI-STRAUSS, 1973, p. 29; apud SEBALD, 2006, p. 137-138). Na poesia herbeckiana, tal técnica se revela nas relações entre os termos, ligados muito mais por aspectos "manuais" do que "lógicos" (SEBALD, 2006, p. 138). Enquanto, geralmente, a literatura costuma ser escrita a partir de uma ideia à qual as palavras precisam ser submetidas - método chamado por Sebald de "regime de uma ideia" (SEBALD, 2006, p. 145) —, o princípio de combinação de Herbeck segue uma lógica alternativa: não há palavra de segunda categoria, cada tom possui a mesma qualidade, cada termo possui sua própria aura 
(SEBALD, 2006, p. 145). Como ainda aponta Sebald, a técnica de bricolage não seria, porém, caraterística apenas da poesia herbeckiana, mas de boa parte da arte produzida por pessoas diagnosticadas como esquizofrênicas. Mais uma vez, Sebald põe em questão a hierarquia estabelecida entre razão e irracionalidade, entre o "pensamento ordenado" e a art brut, lembrando também que Lévi-Strauss fazia questão de insistir que "os meios do pensamento mítico, bastante primitivos em comparação com o arsenal das ciências, não implica de modo algum que sua complexidade seja inferior à da descrição científica” (SEBALD, 2006, p. 138).

O que está em questão não é uma suposta "pobreza do produto" artístico, mas sim a relação provisória, marcada pelo acaso, dos meios utilizados. Enquanto a arte "normal" teria o intuito de chegar a uma "transcendentalização do material", os textos de Herbeck seriam muito mais um "diálogo contínuo com a linguagem, que atribui a responsabilidade pelo próprio desenvolvimento à contingência da realidade" (SEBALD, 2006, p. 138). A arte do bricoleur não procura valores eternos, mas se alimenta de restos e de fragmentos - ou, nas palavras de Lévi-Strauss, "das testemunhas da história de um indivíduo ou de uma sociedade" (1973, p.35; apud SEBALD 2006, p. 138). O bricoleur vive no seu tempo, para seu tempo e o momento atual, e sua arte implica sempre a destruição e reutilização de algo já existente.

Após Freud, Lorenz e Lévi-Strauss, Sebald ainda se reporta a Deleuze e Guattari para fazer jus à poesia de Herbeck. Nesse caso, é o conceito da "literatura menor" - termo cunhado pelos dois filósofos franceses numa análise da obra de Franz Kafka - que considera produtivo para seu ensaio sobre Herbeck. A literatura menor seria uma escrita "contra a cultura" do mainstream, e não "para ela" (SEBALD, 2006, p. 139), sua "pobreza em termos de material é um sinal de um déficit, mas também de sua independência” (SEBALD, 2006, p. 139). Herbeck (assim como o próprio Sebald), quando solicitado a escrever a partir de algum texto literário consagrado, mostrava uma vontade de minar as hierarquias estabelecidas, de desmontar e reduzir algo existente a uma única imagem enigmática: "um poema bem elaborado de Rilke, com as partes poéticas típicas do início do século XX - uma tarde de verão, a vista para a natureza, música de piano, um parque, cheiro de jasmim etc. -, após uma primeira tentativa de reescrever o poema rilkeano, é reduzido [por Herbeck] a um denominador comum, desafiando a tradição interpretativa já consagrada: 'Das Klavier stand 
schräg zum / Fenster und die Musik war 1. Klasse' ['O piano estava posto na transversal frente à / janela e a música foi de primeira categoria']" (SEBALD, 2006, p. 139).

Como em tantos outros dos seus ensaios, a análise que Sebald faz da poesia de Ernst Herbeck vai ao encontro da tendência do próprio germanista-escritor de se posicionar em oposição ao mainstream. Mais uma vez, o germanista ressalta que a "literatura menor", da qual Herbeck é mensageiro e que costuma ser vista como um "fenômeno marginal da nossa cultura" (SEBALD, 2006, p. 140), teria uma importância crucial nos tempos atuais, como um "lugar de esperança" ainda não dominado pela força da ordem administrada que marca o discurso "normal". Muito mais do que "um romance de formação, burguês, repleto de sentido" (SEBALD, 2006, p. 142), a expressão psicótica de Herbeck é capaz de "identificar a complexidade da construção organizada de uma catástrofe histórica como a causa da aparente irracionalidade de nosso destino individual e coletivo" (SEBALD, 2006, p. 142). A doença psíquica de Herbeck - e de todos os esquizofrênicos - e também uma fuga da história, uma incapacidade de acomodar-se e adaptar-se na medida necessária para ser diagnosticado como "normal". Porém, a dimensão trágica de tudo isso é o fato de que tal fuga não leva a uma independência dos acontecimentos históricos. Em outras palavras, a "destruição da personalidade [de Herbeck] que ocorreu após o fim da guerra está intrinsecamente ligada à devastação histórica antecedente" (144). No intuito de corroborar essa visão, Sebald cita Nietzsche: Nos indivíduos, a loucura é algo raro - mas nos grupos, nos partidos, nas épocas, é regra” (apud SEBALD, 2006, p. 143).

A capacidade de Herbeck de expressar o próprio sentimento ambíguo de assentimento em relação à ascensão nazista pré-guerra é comparada por Sebald com a de Ernst Jandl; assim como Jandl, em seu afamado poema "wien: heldenplatz", Herbeck conseguiu expressar a relação entre o "erotismo inibido da pequena família e a euforia política que antecipava a violência que estava a vir" (SEBALD, 2006, 143):

\begin{tabular}{|l|l|}
\hline Ein Erlebnis & Um acontecimento \\
Das war 25. September 1938 & Foi o dia 25 de setembro de 1938 \\
Es war der Einmarsch Hi- & Foi a invasão de Hi- \\
tlers nach Österreich nach & tler na Áustria em \\
Wien. Wir fuhren mit & Viena. Fomos para lá com \\
\hline
\end{tabular}




\begin{tabular}{|l|l|}
\hline einem Laster hinein und & um caminhão e \\
sahen Hitler und die beg- & vimos Hitler e a cidade entusias- \\
eisterte Wienerstadt. & mada de Viena. \\
Reichskanzler Ad. Hitler & O chanceler Ad. Hitler \\
hielt eine Rede in der Er & ministrou seu discurso em que Ele \\
sagte: Wir, die Deutschen und & disse: Nós, os alemães e \\
ich werden den Wienern und & eu vamos ajudar os vienenses e \\
Österreichern helfen und & austríacos e vamos conseguir \\
Euch Arbeit verschaffen. Es & trabalho para vocês. Foi o \\
war das Erlebnis meines & acontecimento da minha vida. \\
Lebens. & \\
$(1977$, p. 126) & \\
\hline
\end{tabular}

Sebald entendeu que, assim como Kafka ${ }^{10}$, Herbeck foi capaz de expressar a "relação simbiótica entre poder e impotência" (SEBALD, 2006, p. 144) - o que, por sua vez, mostra que o poeta doente mental possuía uma ideia bastante clara sobre a relação entre sua própria história e a época histórica em que viveu.

Mesmo não colocando a doença de Herbeck no foco de sua atenção e sem usar sua literatura apenas como pretexto para "se deleitar no excêntrico", Sebald nunca separa os textos dos seus autores; tanto no ensaio sobre Herbeck, quanto em todos os outros reunidos nos dois volumes sobre literatura austríaca, a relação entre texto, autor e contexto é uma dimensão em destaque. Segundo Sebald, não seria possível sentir a "beleza" da poesia herbeckiana sem sentir "a presença física do autor" (140): "Enquanto um artista cresce acima da sua obra, o bricoleur abdica do exercício do seu poder e vive 'debaixo' da língua - nos diversos sentidos que essa preposição permite" (140).

Sebald não possui nenhum modelo teórico uniforme, nenhum "método analítico" para aproximar-se dos textos, mas leva a sério o "desrespeito calculado" em relação a fronteiras teóricas estabelecidas para, assim, lograr no seu intento de trazer à tona as "complexidades" que considera "constitutivas" para a literatura austríaca (SEBALD, 2006, p. 9). Desse modo, embora singular e única, a leitura que Sebald empreende da obra de Herbeck pode ser entendida como paradigmática de toda obra crítica desse germanista, no que tange ao seu método heterodoxo, empático e provocativo.

A recepção e interpretação final dos poemas continua aberta à subjetividade de cada leitor - que, sempre já “acostumado com a ordem linguística” (SEBALD, 2006, p. 134), só

\footnotetext{
${ }^{10}$ Ver Schütte (2005) para uma discussão mais aprofundada sobre a relação entre Kafka e Herbeck.
} 
consegue atribuir aos textos um certo sentido quando as interferências e os deslocamentos da linguagem com os quais se repara deixem surgir imagens que, "apesar de sua aparência compulsoriamente invertida, correspondam minimamente à sua própria fantasia" (SEBALD, 2006, p. 134). A última palavra (interpretativa) fica, assim, com o leitor - e Sebald faz questão que seja assim.

\section{Referências bibliográficas}

BENJAMIN, W. Literaturgeschichte und Literaturwissenschaft. 1931. Disponível em: $<\mathrm{http}$ :/www.textlog.de/benjamin-literaturgeschichte-literaturwissenschaft.html $>$. Acesso em: 23 maio 2016.

BENJAMIN, W. Angelus Novos. Frankfurt: Suhrkamp, 1966.

CARPEAUX, O.M. A história concise da literatura alemã. São Paulo: Faro Editorial, 2013.

GÖRNER, R. The Anatomist of Melancholy: Essays in Memory of W. G. Sebald. Munique: Iudicium, 2003.

HERBECK, E. Der Hase!!!! Ausgewählte Gedichte. Salzburg e Viena: Jung und Jung, 2013.

NAVRATIL, L. (org.). Ernst Herbeck - Im Herbst da reiht der Feenwind. Gesammelte Texte 1960-1991. 3. ed. Salzburg e Viena: Residenz, 1999.

SCHLAFFER, H. Die kurze Geschichte der deutschen Literatur. Köln: Anaconda, 2013.

SCHÜTTE, U. Der Hüter der Metaphysik - W. G. Sebalds Essays über die österreichische Literatur. Manuskripte, vol. 155, 2002, p. 124-129.

SCHÜTTE, U. In einer wildfremden Gegend, W. G. Sebalds Essays über die österreichische Gegenwartsliteratur. In: GÖRNER, R. The anatomist of melancholy: Essays in memory of W. G. Sebald., Munchen: Iudicium, 2003. p. 63-74.

SCHÜTTE, U. Herbeck, nach Kafka. Zur “minderen Literatur” des schizophrenen Dichters Ernst Herbeck. Modern Austrian Literature, vol. 38, no. 34, 2005, p. 37-63. 
SCHÜTTE, U. Für eine "mindere" Literaturwissenschaft. W. G. Sebald und die "kleine" Literatur aus der österreichischen Peripherie, und von anderswo. Modern Austrian Literature,v. 40, n. 4, 2007. p. 83-107.

SEBALD, W.G. Die Beschreibung des Unglücks: zur österreichischen Literatur von Stifter bis Handke. 5. ed. Frankfurt am Main: Fischer, 2006.

SEBALD, W.G. Unheimliche Heimat: Essays zur österreichischen Literatur. 3. ed. Frankfurt am Main: Fischer, 2004.

SEBALD, W.G. Campo Santo. Munique: Carl Hanser, 2003.

STEINLECHNER, G. Nachwort. In: HERBECK, E. Der Hase!!! Ausgewählte Gedichte. Salzburg e Viena: Jung und Jung, 2013.

ZEMAN, H. (org.). Literaturgeschichte Österreichs von den Anfängen im Mittelalter bis zur Gegenwart. Freiburg: Rombach, 2014.

ZEYRINGER, K.; GOLLNER, H. Eine Literaturgeschichte: Österreich seit 1650. Innsbruck: Studienverlag, 2012. 